\title{
EL VALOR ESTRUCTURADOR DE ¿NO? UN ESTUDIO A TRAVÉS DE LA CONVERSACIÓN, LA ENTREVISTA Y EL MONÓLOGO'1
}

THE STRUCTURING VALUE OF THE SPANISH DISCOURSE MARKER ¿NO? A STUDY THROUGH THE GENRES CONVERSATION, INTERVIEW AND MONOLOGUE

\section{Gloria Uclés Ramada}

Universitat de València - Val.Es.Co.

\section{Resumen}

En este artículo se pretenden detallar los valores como estructurador de la información del marcador del discurso ¿no?, un elemento cuyo carácter interpersonal resulta el rasgo de mayor prominencia. Para ello, se lleva a cabo un estudio que se centra en el comportamiento de esta forma en tres géneros discursivos orales: la conversación, la entrevista y el monólogo. A través de un análisis con corpus, se presenta, por una parte, una macrofunción que pretende explicar el valor estructurador de ¿no? desde su naturaleza interactiva y, por otra, un inventario de funciones que recogen la manera concreta en la que este marcador estructura la información.

Palabras Clave: ¿no?, estructuración de la información, marcadores del discurso, español coloquial

\section{Abstract}

In this paper we aim to describe the values of the Spanish discourse marker ¿no?, whose most prominent feature is its interactive nature, as a device to structure information. To do so, an intergeneric study is carried out. Three discursive genres have been chosen, namely, conversation, interview and monologue. Through an analysis with corpus, we present, on the one hand, a macrofunction that aims to explain how ¿no? can develop structuring functions through its interactive nature and, on the other hand, an inventory of functions that cover the specific ways in which this marker structures information.

KEY WORDS: ¿no?, information structuring, discourse markers, colloquial Spanish

\footnotetext{
${ }^{1}$ Este trabajo se enmarca en el proyecto de investigación «La atenuación pragmática en su variación genérica: géneros discursivos escritos y orales en el español de España y América» (FFI2016-75249-P), financiado por el Ministerio de Economía y Competitividad del Gobierno de España.
} 


\section{INTRODUCCIÓN}

En este artículo se pretenden detallar los valores como estructurador de la información del marcador del discurso ¿no?, un elemento cuyo rasgo más prominente lo constituye su carácter interpersonal. Para ello, se lleva a cabo un estudio que se centra en el comportamiento de esta forma en tres géneros discursivos orales: la conversación, la entrevista y el monólogo. A través de un análisis con corpus, se presenta, por una parte, una macrofunción que pretende explicar el valor estructurador de ¿no? desde su naturaleza interactiva y, por otra, un inventario de funciones que recogen la manera concreta en la que este marcador estructura la información.

Una de las ideas que se ha pronunciado repetidamente desde los estudios más iniciales sobre marcadores del discurso hasta publicaciones más recientes es la de que algunos marcadores del discurso, especialmente aquellos que se dan en géneros orales, desarrollan valores expletivos. Se distinguen por no aportar contenido conceptual o procedimental y generalmente la aparición de estos usos se atribuye bien a una falta de habilidad en la producción discursiva de algunos hablantes o bien a su empleo como un apoyo a la hora de construir el discurso, de ahí que algunos autores hayan considerado que los marcadores del discurso puedan adquirir usos expletivos (Fuentes, 1985, Casado Velarde, 1991, Cortés, 1991, Castro, 2003, García Vizcaíno, 2005, Montañez, 2008, 2015, Said-Mohand, 2008, 2014, entre otros). Sin embargo, creemos que la inclusión de elementos tales como los marcadores no es inmotivada. Si los hablantes tienen la posibilidad de prescindir de un elemento y, no obstante, deciden usarlo, detrás de ello debe haber una intención y, por consiguiente, una función que transciende la descripción de vacía de significado o superflua.

Para este estudio, se ha escogido la forma ¿no?, puesto que representa una muestra bastante paradigmática de un marcador del discurso que, además de que se le reconocen valores pragmáticos (véase sección 2), también se ha indicado que puede emplearse con valores expletivos (Cortés, 1991, García Vizcaíno, 2005, Montañez, 2008, 2015). Se estima que en los casos en los que se relega el valor de ¿no? al de una mera forma vacía de significado, en realidad se está produciendo alguna operación relacionada con la estructuración de la información. Precisamente su carácter interactivo se prevé que constituya la base que le permita desarrollar valores centrados en la estructuración.

\section{ESTADO DE LA CUESTIÓN}

\subsection{Sobre el marcador del discurso ¿no?}

Una de las descripciones que resulta casi una constante en los estudios que se ocupan de ¿no? es considerar que su cometido es comprobativo, ya sea como única función de este marcador o junto con un inventario de valores más extenso. En cuanto a las obras que consideran esta función como la principal, se documenta ya en uno de los primeros estudios que trata este marcador con mayor profundidad. Ortega Olivares (1985: 254) lo incluye como parte de los «apéndices comprobativos", que define como elementos que «adosados como están a determinados enunciados-base, se sirve de ellos el hablante para 
conseguir del oyente cierta corroboración». Según este autor, cuando estos marcadores acompañan enunciados aseverativos, la función que desempeñan es la de incitar al oyente a que conteste, ya sea apoyando o rechazando el enunciado del emisor. Por su parte, Portolés y Martín Zorraquino consideran ¿no? como un apéndice comprobativo -subgrupo que se encuentra dentro del grupo de los marcadores conversacionales-, los cuales «le sirven al hablante para conseguir cierta corroboración (que no excluye su rechazo) respecto del segmento del discurso al que remiten» (Martín Zorraquino y Portolés, 1998: 4188). Gille (2006), quien estudia los apéndices conversacionales, considera que ¿no? es un apéndice de intersubjetividad, específicamente con función comprobativa.

Dentro de los autores que reconocen, además de la comprobativa, una nómina más amplia de funciones que puede realizar ¿no?, se encuentra Santos Río (2003) quien distingue dos valores para este marcador: partícula de petición de confirmación y fática. En una línea muy similar, Fuentes (2009) lo denomina un conector ordenador discursivo interactivo que cumple con las funciones de petición de confirmación al interlocutor y fática. Por otra parte, otros dos trabajos que llegan a conclusiones similares son los de García Vizcaíno (2005) y Rodríguez Muñoz (2009). En el primero, García Vizcaíno analiza las funciones de ¿eh? y ¿no? a través de un estudio de corpus y concluye que ¿no? puede desarrollar cuatro valores: comprobativo de pregunta, comprobativo de opinión, fático y expletivo. Por su parte, Rodríguez Muñoz analiza también los marcadores ¿eh? y ¿no? a partir de muestras orales del corpus CREA y distingue tres funciones: comprobativa fáctica, comprobativa de opinión y fática. Centrándose en la posición discursiva a partir del modelo de unidades de análisis para la conversación propuesto por Briz y Grupo Val.Es.Co. (2003) y Grupo Val.Es.Co. (2014), Montañez $(2008,2015)$ distingue tres funciones para ¿no? Considera que al final de la intervención su valor es comprobativo, en mitad de una intervención, tiene una función fática, a la vez que reafirma lo que se dice, y en posición independiente demanda una explicación o una repetición.

Desmarcándose de atribuir un valor comprobativo, encontramos a Briz (1998: 224-225) quien incluye a ¿no? dentro de los marcadores de control del contacto, elementos que, según este autor, "cumplen una función predominantemente expresivo-apelativa y también fática, que se concreta en el discurso bien como reafirmación o justificación del yo, de su actuación o de lo dicho». En un trabajo anterior, Briz (1994), que ya habla de los marcadores de control de contacto, se ocupa específicamente de ¿no? al que atribuye dos funciones: fática y expresivo-apelativa. Domínguez Mujica (2005: 211), dentro de los marcadores de interacción, apunta que ¿no? y el resto de marcadores que se incluyen este grupo «verifican la correferencia o la co-comprensión del argumento que el hablante está presentando", es decir, sirven para explicar algún elemento anterior del discurso del que el hablante considera que debe dar más información.

Respecto a los valores modales que ¿no? también puede desarrollar, se encuentra la atenuación y la petición de afiliación. En diferentes obras se señala su función atenuadora, como en Ortega Olivares (1985), García Vizcaíno (2005), Landone (2009) o Montañez (2015). El valor atenuante de este marcador se ha estudiado con más profundidad en Uclés (2017 y 2018). En cuanto al valor de petición de afiliación se registra en un trabajo específico (Uclés, e.p.). 


\subsection{Sobre la estructuración de la información en marcadores interactivos}

Como se ha visto en la sección anterior, el valor de ¿no? como estructurador de la información no parece constar en la bibliografía consultada. En esta sección, se presentan las funciones estructuradoras que se han recogido en otros estudios sobre otros marcadores conversacionales. Sin embargo, dada la proximidad en cuanto al ámbito de aparición -es decir, se trata de marcadores que, al igual que ¿no?, son propios del registro coloquial y habitualmente son más frecuentes en géneros en los que se establece una comunicación oral-, consideramos necesario incluir también su descripción en cuanto a los valores como estructuradores de la información.

Como ya se recoge en Briz (1993, 1994), Briz e Hidalgo (1998) y de forma más extensa en Briz (1998), este autor habla de «marcadores metadiscursivos o metacomunicativos» y sostiene que "con ellos el hablante parece asegurar el orden y la organización [del discurso]» (Briz, 1998: 202). Dentro de este grupo, hace una distinción entre marcadores de control de contacto (donde incluye ¿no?) y marcadores de control del mensaje. Los primeros se ocupan de regular la interacción con los interlocutores, mientras que los segundos atienden a la estructura informativa. En concreto, los marcadores de control del mensaje tienen un valor demarcativo que consiste en «señalar las partes del discurso" al que se suele sumar una función adicional bien como reguladores de inicio, marca de progresión (correctores, continuadores, reformuladores) o marca de cierre. Algunas de estas funciones estructuradoras -la continuación y la conclusión- coinciden con las que Cortés (1991) atribuye en el análisis a varias formas que se pueden clasificar como marcadores conversacionales (claro, vamos, entonces). Además de estos valores, en el trabajo de Cortés se distinguen también las siguientes funciones relacionadas con la estructuración de la información: la restricción la y corrección.

Domínguez Mujica también reconoce valores textuales a lo que esta autora considera «marcadores de la interacción», si bien no incluye a ¿no? dentro del grupo que los desarrolla. El valor que atribuye a formas como mira, oiga, fijate y sus variantes es el de "orientador de la atención discursiva del interlocutor mediante la cual el hablante asigna relevancia al segmento que sigue» (Domínguez Mujica, 2005: 214). Concretamente, esta función se materializa cuando estos marcadores se emplean para redirigir o expandir un tema que se ha tratado y focalizar la atención del interlocutor sobre un segmento concreto.

A partir de una nomenclatura diferente, consideramos que también Pons (1998), en un trabajo sobre los marcadores oye y mira, trata algunas de sus funciones como estructuradores de la información. Este autor distingue entre función fática estricta orientada hacia la enunciación y función fática interna orientada hacia el enunciado. Dentro de esta última, considera que «el hablante llama la atención de forma ostensiva al oyente sobre la importancia del procesamiento de la cadena inmediatamente anterior o inmediatamente posterior» (Pons, 1998: 219), es decir, que actúan catafórica o anafóricamente. Otro de los valores que Pons también reconoce en uno de los ejemplos que analiza (Pons, 1998: 223, ejemplo 13) es el uso del marcador mira para introducir una matización dentro de una intervención del hablante. 
Como se ha visto en la primera subsección de este apartado, el denominador común que parece observarse en la descripción del marcador ¿no? es el reconocimiento de su valor apelativo y, también en gran medida, de su función comprobativa, es decir, la petición de que el interlocutor ratifique o muestre su acuerdo con una información. Convencionalmente, esta forma se escribe entre signos de interrogación, lo que parece constituir una marca estructural del carácter interactivo de este marcador. El valor que no parece estar recogido en la bibliografía es el de estructurador de la información. Puesto que en este trabajo sostenemos que ¿no? puede desarrollar esta función, se ha dedicado una subsección (2.2) a los estudios que o bien tratan el papel como estructurador de la información que pueden desarrollar los marcadores conversacionales - dentro de los cuales también se puede ubicar ¿no?- o bien tratan formas concretas que también pertenecen a los marcadores conversacionales.

\section{Metodología}

\subsection{Delimitación del objeto de estudio}

El marcador ¿no? se incluye dentro de las «preguntes confirmatòries» en el estudio de Cuenca y Castellà, quienes consideran que "constitueixen construccions mixtes entre l'asseveració i la interrogació» (Cuenca y Castellà, 1995: 68). Creemos que esta categorización sirve solo parcialmente para explicar sus funciones. Obsérvense los siguientes ejemplos:

(1) 1 A: joye! tú mañana si no me he despertado $\downarrow$ me despiertas ¿eh?/ porque a ti te da igual ducharte a las diez que a las once ¿no?

2 B: a mí me da igual a las diez que a las once pero no a laa una $\uparrow$

3 A: hombre claro yo a la una no me voy a levantar que tengo que ir a clase// y tengo que ir a lo del grupo

4 C: la una y ventiocho he dicho ¿no?

5 B: sii no vuelvas a sacar el

6 C: ${ }^{\circ}\left(\right.$ ahora son y veintinueve minutos) ${ }^{\circ}$

Corpus Val.Es.Co. 2.0, Conversación 19, Intervenciones 1-6

(2) $127 \mathrm{~A}:$ = nos vamos a casa de unos amigos/ y le habían tocao $\downarrow$ a mí amiga $\uparrow$ en un- en nosequé/ le habían tocao un montón de preservativos ¿no?/ y me dio a mí pos [unos cuantos ¿no?=]

128 D: [en un sex shop]

129 A: = dice- dicee y llevaba YO pos la bolsa con los preservativos/ y veníamo(s) en el coche y le decía a mí marido mira que si nos para la guardia civil ahora y me dice qué que llevo en la bolsaa/ dice que llevaba por lo menos un puñao de cajas de preservativos// eso es un parto/ macho/// (7?)

Corpus Val.Es.Co. 2.0, Conversación 18, Intervenciones 127-129

En el primero de ellos, coincidimos con Cuenca y Castellà (1995) en cuanto a la incidencia de ¿no? en la modalidad oracional del segmento al que acompaña. En este ejemplo se está manteniendo una conversación sobre la hora a la que deben despertarse las participantes al día siguiente. Se puede ver cómo la hablante $\mathrm{A}$ y la hablante $\mathrm{C}$ utilizan ¿no? al final de sus intervenciones (1 y 4 respectivamente). En ambos casos estamos ante una aseveración seguida por este marcador, lo que provoca que, en realidad, la aseveración se convierta en una pregunta de forma menos prototípica o encubierta a los interlocutores. 
Sin embargo, en el segundo ejemplo, el hablante A introduce el relato de cómo una amiga a la que le habían tocado una gran cantidad de preservativos en un sorteo estaba preocupada por si la Guardia Civil la paraba con estos productos dentro del coche. Aquí el uso de ¿no? no altera la modalidad oracional de los enunciados a los que acompaña, sino que se emplea con un valor estructurador, esto es, su uso responde a las necesidades que tiene el hablante se señalizar límites entre segmentos informativos. Puesto que consideramos que ¿no? tiene estas dos vertientes en las que se comporta de forma diferente respecto a la manera en la que afecta a la enunciación y dado que este estudio está centrado en el plano estructural del discurso, nos ocuparemos solamente de las instancias de este marcador en las que no opera un cambio de modalidad oracional, ya que consideramos que en estos casos ¿no? no opera en el plano de la estructuración de la información.

\subsection{Diseño del estudio}

Como se ha descrito anteriormente, el cometido principal de este trabajo es presentar un inventario de las funciones relacionadas con la estructuración de la información que puede desarrollar el marcador del discurso ¿no? en diferentes géneros discursivos orales. Se pretende de esta manera presentar una categorización completa de sus valores relacionados con la estructuración de la información en la que se tengan en cuenta los diferentes grados de interactividad que presenta en los diferentes géneros discursivos.

Para tales fines, se realiza un estudio con corpus en el que se han escogido tres géneros discursivos que son propicios para la aparición de instancias de ¿no?: la conversación, la entrevista y el monólogo. Estos tres géneros suponen una gradación que engloba de mayor (conversación) a menor interactividad (monólogo), pasando por un punto intermedio (entrevista). Dado que ¿no? es un marcador fático-apelativo, se han seleccionado tanto géneros donde este valor tiene mucha más prominencia, debido a su naturaleza más interpersonal (conversación y, en menor medida, entrevista), como otros donde su función interactiva queda relegada a un segundo plano (monólogo). Por otra parte, este marcador también aparece generalmente en registros coloquiales y mayoritariamente dentro del dominio de lo oral. Estos tres géneros son prototípicamente orales y tienen representaciones coloquiales, que son las que se han escogido para formar parte del corpus.

Los corpus con los que se ha contado constituyen una muestra de español peninsular de cada uno de los géneros analizados. Concretamente, los datos consultados corresponden al corpus de conversaciones coloquiales Val.Es.Co. 2.0 (Cabedo y Pons), el corpus de entrevistas sociolingüísticas de PRESEEA (se han escogido los subcorpus de las ciudades de Valencia y Madrid) y un corpus de transcripciones de monólogos de youtubers de recopilación propia. A partir de un filtrado de ejemplos que contienen la forma tratada (¿no?), se ha realizado un inventario de funciones que puede llevar a cabo dentro del ámbito de la estructuración de la información (sección 5). 


\section{EL ANCLAJE COMO MACROFUNCIÓN ESTRUCTURADORA}

El marcador ¿no? puede desarrollar, entre otros, un valor de estructuración de la información que se emplea para señalizar diferentes situaciones relacionadas con la producción discursiva (véase sección 5). La apelación directa al interlocutor de este marcador provoca que típicamente se realce su función fática en las descripciones de sus funciones pragmáticas (véase sección 2), muestra de ello es el trabajo de Briz (1998), quien considera este elemento dentro de los «marcadores de control del contacto». Es precisamente mediante este valor interpersonal como sostenemos que ¿no? puede adquirir valores estructuradores.

(3) $194 \mathrm{C}$ : = total que digo- digo para una- eso ¿no? Carolina ¿no? y-y nada y se la doy y digo va $\uparrow$ fírmame total que empieza a firmarme $\uparrow$ y no la leo y me la dejo atada $\downarrow$ y no $\mathrm{m}$ ? acordé de leerla $\uparrow$ total que me voy por ahí y me lo encuentro luego y claro $\downarrow$ luego/ tía casi me muero porque me vee y me hace// se me queda así mirando $\uparrow$ y me hace $\downarrow$ esto

Corpus Val.Es.Co. 2.0, Conversación 20

Como muestra el ejemplo anterior, la hablante C está reclamando la atención de su interlocutora (¿no? Carolina ¿no?) mediante el uso de ¿no? antes y después de llamarla directamente por su nombre. Este valor apelativo es, precisamente, lo que confiere a ¿no? su capacidad para delimitar fragmentos en el discurso, pues focaliza la atención del receptor y permite que este se centre en lo dicho anteriormente. El emisor ancla al receptor en diversos puntos de sus intervenciones no solo con una intención meramente fática, es decir, para asegurarse de que el canal está abierto y el receptor le escucha, sino también para indicar al interlocutor que debe estar atento a esta información.

En el fragmento siguiente vemos el uso de ¿no? justo al principio de la intervención de $\mathrm{J}$ (nada/ resulta quee estaba lloviendo/ ¿no?). Este primer segmento informativo constituye el comienzo de un relato motivado por la pregunta anterior de $\mathrm{A}$. J responde diciendo que estaba lloviendo para, a continuación, empezar a contextualizar la situación: cuándo fue (el fin de semana pasado), qué estaba pasando (su hermana se había ido de boda), qué suele hacer el hablante normalmente en ese momento (irse por ahí con el coche los sábados por la tarde). Todas estas informaciones ayudan a ubicar al interlocutor en la historia que va a narrar el emisor, pero no siguen una relación lineal con el hecho de que estuviera lloviendo, algo que el hablante solo retoma posteriormente (y como estaba lloviendo por ahíl no era plan de irse de pafs $\downarrow$ ). Por tanto, el hablante ancla al receptor mediante ¿no?, es decir, señaliza al interlocutor que el hecho de que llueva es una información clave que debe tener en cuenta antes de empezar a dar la información contextual que considera que el interlocutor necesita antes de retomar el relato.

(4) 129 A: [bueno/ ¿y eso] del fútbol qué fue?

$130 \mathrm{~J}$ : nada/ resulta quee estaba lloviendo/ ¿no?/ fue el fin de semana pasao/ yy mi hermana se iba de boda/ yy yo no me acordaba/ y como yo me voy por ahí los sábados por la tarde con el coche/ y estamos en el coche y eso/ pues le dije que claro/ que no tenía coche/ y como estaba lloviendo por ahí/ no era plan de irse de pafs $\downarrow$ ni nada de eso/ aunque cuando llegué ya no llovía $\uparrow$ pero ya puestos $\uparrow$ digo $\rightarrow$ pues vamos a su casa y ya está $§$

Corpus Val.Es.Co. 2.0, Conversación 14 


\section{FUNCIONES DE ¿NO? COMO ESTRUCTURADOR DE LA INFORMACIÓN}

Si se toma como cierta la hipótesis de que ¿no? actúa como marcador que permite al interlocutor localizar anclajes en el discurso que produce el hablante, el paso lógico que se desprende de aceptar esta idea es preguntarse qué es exactamente lo que ancla este marcador y en qué contextos lo hace. En esta sección se presentan los resultados del análisis de los corpus que se han tenido en cuenta para el estudio de las funciones de estructuración de la información del marcador conversacional ¿no? en los géneros conversación, entrevista y monólogo.

Como se ha expuesto en la sección anterior, consideramos que el hilo conductor que permite agrupar todas estas funciones dentro de una misma categoría es el anclaje. Los hablantes sienten la necesidad de dirigir la atención de los interlocutores hacia ciertos segmentos informativos y, en estos contextos orales, se valen de estrategias interactivas que no se suelen rastrear en marcadores propios del escrito. Consideramos que, básicamente, las estrategias de anclaje del interlocutor a la información se clasifican en dos grupos: las que introducen un cambio en el discurso y las que no lo hacen. Dentro de las funciones que implican cambio se encuentran señalizar cambios de movimiento e introducir matizaciones. Por otra parte, los valores de ¿no? que no implican un cambio son demarcativo, acompañar catáforas y mantener el turno.

\subsection{Demarcativo}

El marcador ¿no? se emplea para delimitar segmentos informativos dentro de movimentos más amplios, es decir, representa un límite entre diferentes fragmentos de información dentro de una mismo movimiento, especialmente en intervenciones largas. En estos casos, la señalización de estos fragmentos se hace al final de los mismos a través de este marcador. Esta función demarcativa se ha observado en tres tipos de movimientos, a saber, los narrativos, explicativos y las argumentativos:

a. Movimientos narrativos y explicativos:

Se emplea en fragmentos en los que el interlocutor da cuenta de forma relativamente objetiva de un hecho o una situación, es decir, donde no se expresan opiniones o valoraciones, lo que suele corresponder con segmentos mayoritariamente narrativos o explicativos. Recuperamos el ejemplo 2 presentado anteriormente en la subsección 3.1 en el que la hablante A narra un relato. En la primera intervención, A cuenta cómo a su amiga le había tocado una gran cantidad de preservativos y cómo le había dado parte de estos a este hablante, es decir, se identifican dos segmentos que, si bien están relacionados, aportan informaciones diferentes. Ambos segmentos de información concluyen con un ¿no? que se emplea, precisamente, para delimitar sus fronteras.

(5) $127 \mathrm{~A}$ : = nos vamos a casa de unos amigos/ y le habían tocao $\downarrow$ a mí amiga $\uparrow$ en un- en nosequé/ le habían tocao un montón de preservativos ¿no?/ y me dio a mí pos [unos cuantos ¿no?=] 128 D: [en un sex shop] 
129 A: = dice- dicee y llevaba YO pos la bolsa con los preservativos/ y veníamo(s) en el coche y le decía a mí marido mira que si nos para la guardia civil ahora y me dice qué que llevo en la bolsaa/ dice que llevaba por lo menos un puñao de cajas de preservativos// eso es un parto/ macho/// (7?)

Corpus Val.Es.Co. 2.0, Conversación 18, Intervenciones 127-129

b. Movimientos argumentativos:

Demarca el final de fragmentos en los que se expresan opiniones o valoraciones en movimientos argumentativos. En estos casos, ¿no? presenta frecuentemente también una función atenuante, puesto que en la emisión de opiniones puede estar comprometida la imagen del hablante o la del interlocutor (Briz y Albelda, 2013). En este ejemplo (6), extraído del corpus de entrevistas PRESEEA, se está tratando el examen para poder hacer una residencia que deben pasar los médicos, a tenor de que el entrevistado desempeña esta profesión. Se puede ver en el fragmento cómo tanto entrevistado como entrevistador emiten su opinión sobre este método para la formación de facultativos. El entrevistador lo considera algo atípico, mientras que el entrevistado expone de forma más elaborada su opinión respecto a la manera en la que se plantea y la prueba que se debe pasar. En las intervenciones de ambos, estas valoraciones vienen acompañadas de ¿no? Igual que en el caso de las movimientos narrativos, en fragmentos de habla más largos, se puede ver cómo los diferentes ¿no? que profiere el entrevistado coinciden con fragmentos de información que se delimitan, precisamente, a partir de este marcador, como se puede ver a continuación:

Valoración 1: es algo incongruente + ¿no?

Valoración 2: deberían ofrecer formación continua + ¿no?

Valoración 3: no debería haber una selección + ¿no?

Valoración 4: el sistema de selección es salvaje + ¿no?

(6) E: una cosa atípica ¿no? el método de /

I: eeh sí / es un poco incongruente ¿no? / la opción es tu tuvieras opción a formarte<alargamiento/> // siempre ¿no? / no que<alargamiento/> que para formarte te<alargamiento/ $>$ te hagan un<alargamiento/> / una selección <simultáneo> ¿no? </simultáneo>

E: <simultáneo $>$ una selección $</$ simultáneo $>$ claro

I: una selección que además es<alargamiento/> / es muy salvaje ¿no?

E: sí

MADR_H23_033

\subsection{Señalizar cambios de movimiento}

La función anterior (demarcativo) se ha centrado en describir el uso de ¿no? para delimitar fragmentos de información dentro de un mismo movimiento. No obstante, lo habitual especialmente, dentro de los géneros discursivos orales- es que los emisores no produzcan intervenciones en las que esté implicada únicamente un tipo de movimiento. Se espera que dentro de un mismo turno se usen de manera combinada, bien sea porque se van alternando fragmentos de mayor extensión de diferentes movimientos o porque, dentro de uno de ellos, aparece encapsulado otro movimiento. Estos cambios de movimiento a 
menudo están señalizados a través del marcador ¿no?, que marca el final del primer segmento de información que se produce en un movimiento diferente. Obsérvese el siguiente ejemplo:

(7) I: bueno pues / yo tenía el coche aparcado donde aparcaba todo el mundo / o sea no es que<alargamiento/> / no es que<alargamiento/> / lo tenía mal ¿no? <risas = "l"/> / vamos lo teníamos mal siempre todos ¿no? // $\mathrm{y}<$ alargamiento/> bueno pue<alargamiento/>s / dio la casualidad que<alargamiento/> / llegó la policía / el coche estaba a nombre de mi hermano //

MADR_H12_007

En este fragmento, el entrevistado empieza un relato sobre cómo tuvo un problema con la policía por haber dejado el coche mal aparcado. Justo poco después de empezar la narración, el hablante introduce la siguiente: o sea no es que<alargamiento/> / no es que<alargamiento/> / lo tenía mal ¿no? <risas = "I"/> / vamos lo teníamos mal siempre todos ¿no? El hablante interrumpe momentáneamente el movimiento narrativo para explicar con más detalle cómo tenía el coche aparcado: clarifica que lo tenía mal aparcado, pero se justifica afirmando que todo el mundo aparca así en esa calle. Cuando finaliza este circunloquio prosigue propiamente con la narración de la historia. Es decir, en esta parte de la intervención aparece un movimiento encapsulado dentro de otro. Este, además, está delimitado por varios marcadores del discurso: se puede ver cómo las dos informaciones explicativas que incluye están delimitadas por o sea y vamos respectivamente en el inicio y en ambos casos por ¿no? en el final.

El uso de ¿no? para indicar el cambio entre movimientos se puede dar en diferentes combinaciones. En concreto, se ha encontrado en los siguientes casos: de movimieto narrativo a explicativo, de movimiento argumentativo a explicativo, tópico + valoración + ¿no? y delimitador del final de discurso directo.

\section{a. De movimiento narrativo a explicativo}

Cuando dentro de un movimiento narrativo aparece un movimiento explicativo encapsulado, los fragmentos de este último pueden aparecer delimitados mediante ¿no? De esta manera se puede señalizar al interlocutor el cambio en la naturaleza de los movimientos que utiliza el hablante. En estos casos, el cambio de movimiento supone, además, una disrupción de la linealidad del relato, que se ve interrumpido por una serie de elementos que permiten al hablante contextualizar mejor la historia que está contando, por lo que la necesidad de señalizar estos cambios al interlocutor se hace mayor. Esta estrategia se ilustra en el ejemplo 8, donde L está contando cómo, mientras estaba parada con el coche en un cruce, otro coche le golpeó por detrás. Esta narración, sin embargo, se interrumpe momentáneamente para especificar exactamente cómo y por qué estaba parada. Por tanto, dentro de la movimiento narrativa la hablante introduce un pequeño movimiento explicativo que marca acompañado por dos ¿no?, los cuales delimitan los dos fragmentos informativos que constituyen dicho movimiento ( $y$ eso que se pone en verde $\uparrow$ y no puedes seguir $\uparrow$ ¿no? pues eso sin poner la marcha ni nada $\uparrow / /$ con el freno tocándolo te ibas pa(ra) bajo ¿no?). 
(8) L: yy va yy/// estábamos en el puente de viveros $\uparrow /$ y había follón// y paraos en el semáforo $\downarrow$ y eso que se pone en verde $\uparrow$ y no puedes seguir $\uparrow$ ¿no? pues eso sin poner la marcha ni nada $\uparrow / /$ con el freno tocándolo te ibas pa(ra) bajo ¿no? sin poner marcha/// yy detrás de míi iba una chica $\uparrow$ / con un $\rightarrow$ suzuki/ y era novata/// Y ME HA PEGAO POR DETRÁS $\downarrow$

Corpus Val.Es.Co. 2.0, Conversación 16, Intervención 81

b. De movimiento argumentativo a explicativo

Otro de los casos en los que se ha observado que ¿no? señaliza un cambio de movimiento es entre el argumentativo y el narrativo. Muestra de ello es el ejemplo 9, donde el entrevistador pregunta al entrevistado sobre qué considera que define la amistad. Este tipo de preguntas requieren una respuesta argumentativa que, efectivamente, el entrevistado proporciona. Sin embargo, dentro de la movimiento argumentativo se incluye un fragmento explicativo, que está delimitado por ¿no? ( $y<$ alargamiento/> realmente un amigo te das cuenta cuando<alargamiento/> / cuando te vienen<alargamiento/> las cosas malas ¿no?). Este fragmento explicativo está precedido por un alegato sobre la importancia de la amistad en la vida las personas y, posteriormente, el hablante prosigue exponiendo la importancia precisamente de mantener la amistad durante los malos momentos, ambas, pues, movimientos argumentativos entre las que se inserta el fragmento explicativo.

(9) E: eso quisiera que me dijeses / eeh ¿en qué consiste esa<alargamiento/> / eeh qué es para ti esa la amistad? ¿qué es un amigo? / ¿cuál es<alargamiento/>? /

I: pues<alargamiento/> ¿un amigo<alargamiento/>? <silencio/> pues para mí / yo creo que es de las cosas más importantes que hay en esta vida / o sea tener amigos // y<alargamiento/> realmente un amigo te das cuenta cuando<alargamiento/> / cuando te vienen<alargamiento/> las cosas malas ¿no? // o sea yo siempre he dicho // <cita $>$ hay que estar a las duras y a las maduras </cita> / o sea colegas de<alargamiento/> copeo y demás hay mucho / pero luego cuando<alargamiento/> tienes algún problema y demás el que veas que<alargamiento/ $>$ / el que está a tu lado el que te $<$ alargamiento/ $>/ /$ te da<alargamiento/> ánimos <ininteligible/> o te da alguna solución cuando tú<alargamiento/> crees que<alargamiento/> está todo<alargamiento/> // perdido pues / realmente ahí yo creo es donde // se ve la amistad

MADR_H12_007

c. Tópico + valoración + ¿no?

Se incluyen dentro de esta categoría las instancias en las que ¿no? delimita el final de una valoración. A diferencia de las movimientos argumentativos en las que el marcador delimita segmentos en un movimiento de la misma naturaleza, en esta la valoración aparece precedida de un fragmento objetivo. El hablante primero produce un segmento declarativo y, a continuación, realiza una valoración sobre lo dicho anteriormente. En este tipo de estructuras también se detecta, junto al papel como estructurador, la función de atenuante (Briz y Albelda, 2013) de la opinión proferida.

Un caso de este tipo de patrón lo constituye el ejemplo 10, que pertenece a un monólogo de una youtuber en el que habla sobre curiosidades relacionadas con el sexo. En este fragmento concreto comenta que la eyaculación precoz hasta el momento no tiene 
remedio médico y luego hace un comentario valorativo en el que da una posible alternativa para atajar el problema (podríais intentar pensar en los Teletubbies mientras estáis haciéndolo a ver si eso por retrasa un poco la cosa ¿no?). El comentario se cierra con ¿no? y el fragmento queda aislado de la exposición de los hechos puesto que, como se puede observar, a continuación, la hablante cambia de tema (el siguiente punto habla de los orgasmos).

(10) pero que el tema de la eyaculación precoz no tiene cura y que este problema afecta a uno de cada cuatro hombres o sea que tampocoo es una cosa muy extraña y por lo visto aparece más a menudo de lo que nos creemos pero que por ahora no tiene solución podríais intentar pensar en los Teletubbies mientras estáis haciéndolo a ver si eso por retrasa un poco la cosa ¿no? el siguiente punto habla de los orgasmos y dice que son más intensos en condiciones más cálidas

Herrejón_Curiosex vol 1

En contextos altamente interactivos, como es el caso de la conversación coloquial, se detecta un movimiento similar. Sin embargo, el movimiento, que en estos casos es frecuentemente narrativo, lo produce un hablante y es el receptor quien formula una valoración acompañada de ¿no? Se encuentran instancias de esto en relatos sobre terceras personas, donde el interlocutor valora algún elemento de la narración. Este es el caso del ejemplo 11, en el que M cuenta a MJ el encuentro con un conocido suyo, Juanjo. Este le dice a $\mathrm{M}$ que se ha enamorado de una chica y que, además, hay otras dos chicas de la facultad que se quieren tener relaciones sexuales con él, ante lo que M muestra incredulidad. MJ responde al relato dando una valoración del comportamiento de Juanjo, delimitada por ¿no? (iqué capullo! ¿no?). En otras ocasiones el relato puede incluir al propio hablante, como en (12). C está hablando de que en una salida al campo organizada por su facultad les estaban explicando qué hacer en caso de un terremoto, a lo que $\mathrm{B}$ responde con una valoración de este hecho ([que ánimos] ¿no?) en el que ¿no? también marca el final de la misma.

(11) $\mathrm{M}:$ bueno/ va $\rightarrow$ resulta que vi a Juanjo $\uparrow / / \mathrm{e} \rightarrow$ conocido por todo el muundo $\rightarrow$ por toda la facultad $\rightarrow$ sobre todo por todos los que estamos aquí enn-/ en $\rightarrow / /$ peCANdo ((dentro)) en $\rightarrow$ cafetería $\downarrow / /$ yy nada// me viene $\uparrow$ y estaba muy emocioNAAdo $\rightarrow /$ muy feLIIZZ $\downarrow /$ porque se había enamoRAdo $\rightarrow / / /$ y yo $\uparrow$;fijate que casualidad! ¿no?/ qué- qué- iqué cosa más rara en él! $\downarrow / /$ me viene $\rightarrow /$ me cooge/ de la MAno $\rightarrow$ taal $\rightarrow$ porque estoy muy enamoRAdo $\downarrow$ / esta semana he conocido al amor de mi Vlda $\rightarrow / / \mathrm{e} \rightarrow$ / ¡no es gran cosa!/ es $\mathrm{fEIlla} \rightarrow \mathrm{tal} \rightarrow$ pero tiene un gran corazóon/ dice ¿sabes lo mejor de todo?// que $\rightarrow$ / aquí en la facultad hay dos tías que me quieren follar $\uparrow / / /$ me quedo así/ y digo ¿qué?/ digo pero ¿te lo han dicho?// ¡NOO! pero se les noota $\downarrow / /$ y yo diciéndole $\rightarrow$ tlh/ th// iquítate el mocarrón $\downarrow$ tío!

MJ: ¡qué capullo! ¿no?

Corpus Val.Es.Co. 2.0, Conversación 23, Intervenciones 1-2

(12) 327 C: pues estábamos en el campo en la facultad de ciencias estábamos $\downarrow / / /$ estaba por allí química/ matemáticas// danza $\uparrow /$ bellas artes $\rightarrow$

328 B: jjolin! chica/ todo un lujo

329 C: y negros un montón $\downarrow / / /$ lo primero que nos explican cuando llegamos que tenemos que hacer $\uparrow$ si hay un terremoto $\uparrow /$ donde nos tenemos que meter y yo [jahh!]

330 B: [que ánimos] ¿no?

Corpus Valesco 2.0, Conversación 25 


\section{d. Delimitador del final de discurso directo}

El marcador ¿no? aparece frecuentemente después de un segmento en el que se reproduce discurso directo. Esto puede corresponder bien a una recreación de una conversación anterior (ejemplo 13) o a la expresión de un pensamiento del hablante (ejemplo 14). El fragmento en estilo directo puede ir introducido -o no- de un verbo dicendi. Se emplea ¿no? en posición final para indicar el cierre del fragmento en discurso directo. En estos casos, el valor delimitador de ¿no? puede estar acompañado de la función de petición de afiliación por parte del hablante al interlocutor (Uclés, e. p.). Aunque no se considera su uso propiamente como estructurador de la información, este valor se recoge para el marcador ¿sabes? en Montañez (2015: 279)

(13) entonces me he metido en un artículo que se llama "Esta es la duración ideal del coito según los expertos" y he dicho vale pues cuéntame más ¿no? y lo que dice este artículo es que la duración del coito pero es decir sólo del coito ya son trece minutos

Herrejón_Curiosex vol 1

(14) I: [...] pues es yo qué sé si vas a su casa pues a lo mejor / <cita $>$ ten cuidado no<alargamiento/> no toques ese mueble que es del siglo dieciocho de<alargamiento/ $></$ cita $><$ risas = "todos"/ $>$ ¿no? $<$ entre_risas $>$ pero<alargamiento/> </entre_risas $>$ si no poco más ¿no? <risas = "E"/> si no poco más

MADR_H22_026

En ocasiones, el discurso directo se completa con una aportación del hablante que no corresponde a las palabras dichas por terceros, típicamente (y) no sé qué (no sé cuántos). En estos casos, también se puede emplear ¿no? como delimitador del fin del discurso reportado precisamente después de este añadido. Aunque estos añadidos no representen una reproducción de algo dicho en estilo directo, al delimitar justo después de estas fórmulas y no donde realmente acaba el discurso directo, los hablantes sí consideran que pertenece a esta dimensión, como se puede observar en los ejemplos 15 y 16.

(15) E: ¿sí? ¿Os <simultáneo> lleváis bien? </simultáneo>

l: <simultáneo $>$ luego tenemos $</$ simultáneo $>$ alguna discusión por la ropa porque $<$ cita $>$ me has cogido esto y yo te he cogido esto </cita> y no sé qué ¿no? / como somos chicas y<alargamiento/> y<alargamiento/> / pero bien

(16)

MADR_H22_026

168 A: dice porque [yo=]

169 B: [((pues no))]

$170 \mathrm{~A}:=$ te conozco y estudio mucho $\uparrow /$ no sé qué no [sé cuántos=]

171 B: [pues nada]

$172 \mathrm{~A}:=$ ¿no?// digo mira pues yo creo que ese esfuerzo $\uparrow$ te vale la pena de todas las maneras $\uparrow /$ porque te viene bien $\downarrow /$ entonces yo no te voy a decir que con eso vayas a aprobar $\uparrow$ pero como el esfuerzo te vale la pena $\uparrow$ pues ya está $\downarrow$ coges y lo haces [y punto]

Corpus Valesco 2.0, Conversación 31, Intervenciones 168-172 


\subsection{Introducir matizaciones}

En esta categoría se incluyen los casos en los que los hablantes sienten la necesidad de matizar o ampliar una información que justamente ha sido pronunciada antes de la puntualización que se hace sobre ella. Pons (1998: 223) también habla de la función del marcador mira para introducir una matización. Parece tener una definición similar a la aquí presentada, pero este autor categoriza dicha función como un valor modal y no estructurador.

En estos casos, ¿no? se emplea para señalizar el final de las matizaciones. En este tipo de fragmentos informativos de matización, no solo el final se delimita, sino que en ocasiones también en el principio de la puntualización se observa la presencia de marcadores como bueno u o sea, si bien es cierto que las puntualizaciones también pueden aparecer sin marcadores u otro tipo de elementos lingüísticos o extralingüísiticos que designen su apertura. El ejemplo 17 constituye una muestra de la estructura bueno + matización + ¿no? La hablante A sostiene que, aunque se estipulan ciertos metros cuadrados en las escuelas por niño matriculado, esta norma no se cumple en la realidad, sobre lo que seguidamente puntualiza bueno $\downarrow$ en algún sitioo puede que HAYA $\downarrow$ pero que- que es una excep[ción ¿no? =], es decir, encontramos una puntualización delimitada entre dos marcadores del discurso. La estructura o sea + matización + ¿no?, como se ha señalado, se presta también a encapsular una puntualización. Muestra de ello es el ejemplo 18, donde el hablante está describiendo qué haría si le tocara la lotería. Afirma que lo primero sería comprarse una moto rápidamente, para especificar a continuación con el segmento o sea / al día siguiente ¿no? Por último, en 19 se registra un caso sin marcador que señalice el inicio de la matización, es decir, con la estructura matización + ¿no?, en el que ante las preguntas sobre la relación que mantiene con sus compañeros de clase a la entrevistada, esta contesta diciendo que tiene amigos, para aclarar seguidamente después de una pausa breve: compañeros ¿no?

(17) $\mathrm{A}$ : = tener un si- un gabinete sicológico / claro $\downarrow /$ luego $\uparrow$ que las instalaciones sean buenas $\uparrow$ no sé cuántos metros cuadrados te piden por niño $\rightarrow$ pero que? s/ una animalada eso $\uparrow$ [que=]

B: [síl]

$\mathrm{A}:=$ dices $\uparrow$ bueno/ oiga/ por favor $\downarrow$ [que ellos no necesitan]

B: [que eso- eso no lo hay $\uparrow$ ] nii jvamos!

A: que no lo hay en ningún sitio $\uparrow$ / bueno $\downarrow$ en algún sitioo puede que HAYA $\downarrow$ pero que- que es una excep[ción ¿no?=]

Corpus Valesco 2.0, Conversación 1, Intervenciones 125-129

(18) I: [...] pues me tocan doscientos millones / pues sí / me compraría pues una moto rápidamente / o sea / al día siguiente ¿no? <risas= "I"/> / no me lo pensaría dos veces

VALE_H13_020

(19) E: relación tienes con los <simultáneo $>$ compañeros? </simultáneo $>$

l: <simultáneo $>$ con mis </simultáneo $>$ compa<simultáneo $>$ ñeras $</$ simultáneo $>$

E: <simultáneo $>$ ¿son $</$ simultáneo $>$ amigos o<alargamiento/>?

l: sí / sí tengo<alargamiento/> amigos / compañeros ¿no? así cercanos / lo que pasa que<alargamiento/> hay compañeros que es eso que son muy competitivos

MADR_H22_026 


\subsection{Acompañar catáforas}

Entre una introducción general a un tema u opinión general y su desarrollo más concreto inmediatamente posterior, se puede introducir ¿no? En estos casos, se podría sostener que el marcador se emplea para señalizar una catáfora cuya culminación es inminente, puesto que se resuelve justo después de su empleo. Esta estrategia se puede dar tanto cuando la catáfora la conforma una proforma, como en el ejemplo 20 en el que tres hablantes hablan sobre la preparación de oposiciones de profesorado de secundaria y $\mathrm{B}$ hace referencia a unos contenidos que ha estudiado en un máster. Cuando $\mathrm{C}$ le pregunta exactamente qué ha visto en el máster, B introduce la explicación mediante esto ¿no? seguido de una explicación sobre los contenidos que se impartían en una asignatura. En otros casos, las catáforas pueden adoptar formas más específicas sobre el tema que se va a tratar, como en (21), donde durante varias intervenciones el entrevistador pregunta por las diferencias entre la infancia de la entrevistada y la de su madre. En este fragmento, la entrevistada habla sobre cómo las diferencias se notan arquitectónicamente con edificios nuevos y también con la manera en la que los niños juegan. Lo introduce mediante una catáfora acompañada de ¿no? (el juego ¿no?) para posteriormente exponer las diferencias entre cómo pasaban el tiempo de ocio en la infancia su madre y ella. Esta función de señalización de catafóras a través de marcadores discursivo también se registra para oye y mira en Pons (1998: 219).

(20) B: $[(())] / /$ esto hemos visto en el máster /

A: [y tercero $\uparrow]$

B: ees una asignatura

A: [eeh] la unidad didáctica $\S$

B: §sí

C: ¿((que qué has)) visto en el máster?

B: esto ¿no? las des- las destrezas y estrategias orales / asíi / ((e- laa))

A: te lo [puntúan todo]

B: [a la hora] dee una presentación pues la [dee- cómo vas vestido cómo te mueves cómo hablas el tono $\rightarrow$ ]

Corpus Valesco 2.0, Conversación 42, Intervenciones 480-488

(21) las diferencias a lo mejor de<alargamiento/> / de<alargamiento/> algún edificio nuevo mm la<alargamiento/> mm pues que / habían construido más edificios el juego ¿no? ella me contaba que a lo mejor / iban y se juntaban todas las niñas que vivían en la misma calle calle<alargamiento/> / al final de la calle donde se encontraban en el cruce de dos calles y se ponían a jugar a la cuerda a la comba al pañuelo y tal / nosotros nos íbamos un poco más a nuestra bola para que no nos vigilasen tanto ¿no? e<alargamiento/>llas estaban todas juntitas en la misma calle / o les mandaban ir a por agua al pozo<alargamiento/> nosotras / pues eso no porque teníamos agua del grifo ¿no?

MADR_M12_010

\subsection{Mantener el turno}

Otra de las funciones estructurales que desempeña el marcador ¿no? es la de mantener el turno ante cualquier tipo de problema en la producción de su discurso que el hablante perciba que pueda ser aprovechada por los interlocutores para ganar el turno. Este valor suele darse cuando aparece acompañado de vacilaciones, alargamientos o reinicios que atienden a una dificultad del hablante para encontrar la palabra que quiere emplear y que, por tanto, entorpecen la producción discursiva. Muestra de ello es el ejemplo 22, en el que el hablante tiene manifiesta dificultad en proseguir su discurso, lo que se refleja en la triple 
repetición de cuando (cuando Youtube ¿no? cuando- cuando subir vídeos), acompañado por el empleo de ¿no? que expresa la voluntad de seguir con el turno. También puede aparecer justo después del momento en el que el hablante retoma el hilo de la intervención, con lo que se marca el deseo de mantener el turno. Precisamente eso ocurre en el ejemplo 23, donde la hablante comenta las salidas de su futuro trabajo como decoradora de interiores. En este caso, se atasca en un fragmento (un pie<alargamiento/> a $<$ palabra_cortada/> <vacilación/> apoyado ¿no?) y cuando consigue encarrilar su discurso, lo acompaña de un ¿no? que parece indicar que reclama el turno.

(22) en este vídeo quiero hablar de una cosa que me preocupa bastante me preocupan hoy me ha afectado a mí la verdad en este tiempo que llevo en Youtube que es cuando Youtube ¿no? cuando- cuando subir vídeos pasa de ser un hobby una diversión a pasa a ser una obligación

Perxitaa_youtube ocio negocio

(23) I: también lo bueno es que este tipo de trabajos solo lo permiten personas que tienen<alargamiento/> dinero porque una<alargamiento/> / persona normal < ruido_fondo $>$ se decora la casa </ruido_fondo $>$ por sí misma ¿no? entonces

E: uhum /

I: todavía tienes como <risas = "l"/> un pie<alargamiento/> a $<$ palabra_cortada/ $><$ vacilación/> apoyado ¿no? para decir <cita> bueno / todavía<alargamiento/> / si hay gente que se lo puede permitir y que lo quiere pues a lo mejor sí que /

E: sí

I: hay trabajo ¿no? </cita> so < palabra_cortada/> hay que buscarlo / si no<alargamiento/> /

MADR_M12_010

Parece especialmente remarcable señalar el hecho de que aparezca en monólogos, debido precisamente a su carácter, en principio, no interactivo. No se esperaría encontrar estrategias de mantenimiento del turno, dado que el hablante no va a ser interrumpido. Ello es especialmente cierto en el corpus del que se han obtenido los ejemplos, puesto que se conforma de youtubers que incluso suelen grabarse solos y que, además, pueden editar los vídeos y cortar las partes que sean problemáticas en cuanto a la producción lingüística. En menor medida, también es llamativo encontrarlo en las entrevistas de PRESEEA donde, a pesar de que sí existe interacción entre los hablantes, el papel asignado a cada uno de ellos limita ampliamente el desarrollo de la interacción, por lo que los robos de turno no son esperables. Sin embargo, ante un problema de producción, los entrevistados se aseguran de marcar su voluntad de mantener el turno.

\section{CONSIDERACIONES FINALES}

El objetivo de este artículo ha sido el de presentar de manera detallada las funciones de ¿no? como estructurador de la información. Para ello, como se trata de un marcador que aparece eminentemente en el plano oral y formalmente constituye una interpelación al interlocutor, se han escogido tres géneros orales de mayor a menor interactividad (conversación, entrevista y monólogo) con el fin de cubrir la mayor parte del espectro de sus posibles manifestaciones. En primer lugar, se establece que el denominador común que parece permitir que ¿no? desarrolle funciones estructuradoras es su naturaleza fática: la macrofunción de anclaje del receptor a partes concretas de la intervención del hablante. Se considera que este marcador, a través de la llamada de atención al interlocutor, es capaz de señalar estos fragmentos de información relevantes que el receptor debería tener en cuenta; es decir, lo ancla al discurso. 
En cuanto a las manifestaciones concretas de este anclaje, se encuentran cinco funciones: demarcativo, señalizar cambios de movimiento, introducir matizaciones, acompañar catáforas y mantener el turno. De estas cinco funciones, podemos encontrar dos ejes: uno en el que se delimita información sin que se produzcan cambios y otro en el que la demarcación está acompañada también de algún tipo de alteración en el discurso. En el primero se encuentran la función demarcativo, en la que ¿no? delimita segmentos informativos dentro de movimientos del mismo tipo, y la función mantener el turno, en la que los hablantes señalizan que su producción discursiva no ha acabado a fin de evitar un potencial robo de la palabra. En el segundo eje, ¿no? señaliza bien la introducción una otro movimiento diferente, el final de un fragmento en estilo directo o la alteración de la producción lineal de información.

\begin{tabular}{l}
\hline Funciones de ¿no? como estructurador de la información \\
\hline Demarcativo \\
\hline Señalizar cambios de movimiento \\
De movimiento narrativo a explicativo \\
De movimiento argumentativo a explicativo \\
Tópico + valoración + ¿no? \\
Delimita el final del discurso directo \\
\hline Introducir matizaciones \\
\hline Acompañar catáforas \\
\hline Mantener el turno \\
Figura 1: Cuadro-resumen de las funciones estructuradoras de ¿no?
\end{tabular}

Como se puede observar, la macrofunción de anclaje que se adscribe a ¿no? tiene dos vertientes. En los casos en los que se produce un cambio, el hablante utiliza este elemento lingüístico para alertar al interlocutor mediante una llamada a su atención ante un segmento informativo que comporta un cierre -como en la delimitación del estilo directo- o una novedad -como en los cambios de movimiento-. Por otra parte, ¿no? también aparece en fragmentos en los que no hay cambios, aunque esto no quiere decir que el marcador sea superfluo en estas instancias. La delimitación demarcativa permite separar segmentos informativos distintos y el reclamo para mantener el turno responde a la regulación de la interacción.

Finalmente, a pesar de que no representan propiamente el foco de este artículo, no pueden pasarse por alto algunas cuestiones ligadas a la función estructuradora de ¿no?:

a) Su aparición en ciertos contextos favorece que la función de estructurador de la información vaya acompañada de valores modales también codificados por este marcador: la atenuación y la petición de afiliación. En los movimientos argumentativos la función modal prevalente es la atenuación, mientras que en movimientos narrativos o explicativos se pueden encontrar casos en los que también se detecta un valor de petición de afiliación.

b) Se han encontrado instancias de la función del mantenimiento de turno en los monólogos de Youtube, lo cual a priori no sería esperable. Un robo de turno sería altamente inusual, puesto que en muchos casos ni siquiera hay un interlocutor presente 
en el momento de la grabación del vídeo. Sin embargo, en estas situaciones los hablantes parecen emplear marcadores interactivos como señal clara hacia un potencial interlocutor de su voluntad de seguir con el discurso, anticipando una posible amenaza a ser interrumpidos. De esta manera, parecen recrear o anticipar cierta interactividad en contextos de habla unilaterales, al menos durante el momento de grabación. Se considera, sin embargo, necesario un realizar un estudio con mayor profundidad que trate este tema y que pueda aportar más luz sobre los mecanismos presumiblemente interactivos en situaciones que, en principio, no lo son.

c) En la función introducir matizaciones se observan una serie de patrones recurrentes que cuentan con ¿no? como elemento que señaliza su final, a saber, bueno + puntualización + ¿no? o o sea + puntualización + ino? Cabría, por tanto, la posibilidad de considerarlos, desde la gramática de construcciones (Gras, 2011), dos construcciones y tratarlos desde esta perspectiva.

\section{REFERENCIAS BIBLIOGRÁFICAS}

Briz Gómez, Antonio (1993): «Los conectores pragmáticos en la conversación coloquial (II): su papel metadiscursivo», Español Actual, 59, 39-56.

Briz Gómez, Antonio (1994): «Hacia un análisis argumentativo de un texto coloquial: La incidencia de los conectores pragmáticos», Verba, 21, 369-395.

Briz Gómez, Antonio (1998): El español coloquial en la conversación. Esbozo de pragmagramática, Barcelona, Ariel.

Briz Gómez, Antonio y Marta Albelda Marco (2013): «Una propuesta teórica y metodológica de la atenuación lingüística en español y portugués. La base de un proyecto en común (ES.POR.ATENUACIÓN)», Onomázein, 28, 288-319.

Briz Gómez, Antonio y Antonio Hidalgo Navarro (1998): «Conectores pragmáticos y estructura de la conversación", en Martín Zorraquino, María Antonia y Estrella Montolío Durán, coords., Los marcadores del discurso. Teoría y análisis, Madrid, Arco Libros, 121-142.

Briz, Antonio y Grupo Val.Es.Co. (2003): «Un sistema de unidades para el estudio del lenguaje coloquial», Oralia, 6, 7-61.

Cabedo Nebot, Adrián y Pons Bordería, Salvador, eds. (s. a.): Corpus Val.Es.Co. 2.0. [en línea]: http://www.valesco.es [Consulta: 18/09/2018].

Casado Velarde, Manuel (1991): «Los operadores discursivos es decir, esto es, o sea y a saber en español actual: valores de lengua y funciones textuales», Lingüística Española Actual, 13, 87-116.

Castro, María Inés (2003): «La noción de conexidad y el conectivo o sea», Español Actual, 80, 6177.
Cortés Rodríguez, Luis (1991): Sobre conectores, expletivos y muletillas en el español hablado, Málaga, Librería Ágora.

Cuenca, Maria Josep y Josep Maria Castellà (1995): «Una caracterització cognitiva de les preguntes confirmatòries (question tags)", Caplletra, 18, 65-84.

Domínguez Mujica, Carmen Luisa (2005): Sintaxis de la lengua oral, Mérida, Consejo de Desarrollo Científico, Humanístico y Tecnológico.

Fuentes Rodríguez, Catalina (1985): Sintaxis oracional, Sevilla, Alfar.

Fuentes Rodríguez, Catalina (2009): Diccionario de conectores y operadores del español, Madrid, Arco Libros.

García Vizcaíno, María José (2005): «El uso de los apéndices modalizadores ¿no? y ¿eh? en el español peninsular», en Sayahi, Lofti y Maurice Westmoreland, eds., Selected proceedings of the II workshop on Spanish sociolinguistics, Somerville, Cascadilla Press, 89-101.

Gille, Johan (2006): "“Este hombre se debe de mover, vamos": un primer acercamiento a los apéndices conversacionales», en Olsen, Michel y Erik H. Swiatek, eds., XVI Congreso de Romanistas Escandinavos, Roskilde, Roskilde Universitet, [en línea]: $<$ http://ojs.ruc.dk/index.php/congreso/article/ view/5244>

Gras Manzano, Pedro (2011): Gramática de Construcciones en Interacción. Propuesta de un modelo y aplicación al análisis de estructuras independientes con marcas de subordinación en español, Tesis doctoral, Universitat de Barcelona, Departamento de Filología Hispánica. 
Grupo Val.Es.Co. (2014): «Las unidades del discurso oral. La propuesta Val.Es.Co. de segmentación de la conversación (coloquial)», Estudios de Lingüística del Español, 35, 13-73.

Landone, Elena (2009): Los marcadores del discurso y cortesía verbal en español, Berna, Peter Lang.

Martín Zorraquino, María Antonia y José Portolés (1999): «Los marcadores del discurso» en Bosque, Ignacio y Violeta Demonte, eds., Gramática descriptiva de la lengua española, Madrid, Espasa-Calpe, 4051-4213.

Montañez Mesas, Marta Pilar (2008): «El apéndice ¿no? en la conversación coloquial española», Boletín de Filología, 43, 117-174.

Montañez Mesas, Marta Pilar (2015): Marcadores discursivos conversacionales y posición final. Hacia una caracterización discursiva de sus funciones en unidades del habla, Tesis Doctoral, Universitat de València, Departamento de Filología Española.

Ortega Olivares, Jenaro (1985): «Apéndices modalizadores en español: Los 'comprobativos'», en Montoya Martínez, Jesús y Juan Paredes Núñez, eds., Estudios Románicos dedicados al profesor Andrés Soria Ortega. Vol. 1, Granada, Universidad de Granada, 239-255.

Pons Bordería, Salvador (1998): «Oye y mira o los límites de la conversación». En Martín Zorraquino, María Antonia y Estrella Montolío Durán, coords., Los marcadores del discurso. Teoría y análisis, Madrid, Arco Libros, 213-228.

PRESEEA (2014-): Corpus del Proyecto para el estudio sociolingüístico del español de España y de América. Alcalá de Henares: Universidad de Alcalá, [en línea]: http://preseea.linguas.net [Consulta: 18/09/2018].

Rodríguez Muñoz, Francisco (2009): «Estudio sobre las funciones pragmadiscursivas de ¿no? y ¿eh? en el español hablado», Revista de Lingüística Teórica y Aplicada, 47, 83-101.

Said-Mohand, Aixa (2008): «Aproximación sociolingüística de uso de entonces en el habla de jóvenes bilingües estadounidenses", Sociolinguistic Studies, 2, 97-130.

Said-Mohand, Aixa (2014): «Los marcadores del discurso en el español hablado en los Estados Unidos: estado de la cuestión», Tonos Digital, 26 [en línea]: $<$ https://www.um.es/tonosdigital/znum26/sec ciones/estudios-23marcadores_aixa_said.htm>.

Santos Río, Luis (2003): Diccionario de partículas, Salamanca, Luso-española de Ediciones.

Stivers, Tanya (2008): «Stance, alignment, and affiliation during storytelling: when nodding is a token of affiliation», Research on Language and Social Interaction, 41, 31-57.

Uclés Ramada, Gloria (2017): «La atenuación en Gandía Shore: los marcadores conversacionales ¿eh?, ¿no?, ¿sabes? y ¿vale?», en Albelda Marco, Marta y Wiltrud Mihatsch, eds., Atenuación e intensificación en géneros discursivos, Madrid/Frankfurt, Iberoamericana/Vervuert, 265-282.

Uclés Ramada, Gloria (2018): «La atenuación de los marcadores de control de contacto en PRESEEA. Un estudio comparativo entre España y México», RILCE.

Uclés Ramada, Gloria (en prensa): «¿No? y ¿sabes? como elementos de petición de afiliación». 